\title{
DESENVOLVIMENTO SUSTENTÁVEL: HARMONIA TRIPARTIDA NA AMAZÔNIA LEGAL
}

\author{
Antonio Luis dos Santos Filho ${ }^{1}$
}

Resumo: O presente estudo tem por objetivo analisar os desafios a serem superados para que se alcance o desenvolvimento sustentável na Amazônia Legal. De um lado, a busca incessante do crescimento econômico, do outro, a necessidade de vitalidade social e, por fim, a exigência universal da qualidade ambiental. Destarte, com base em uma investigação documental-bibliográfica na doutrina, jurisprudência e legislação nacional e internacional, demonstra-se que a sustentabilidade ambiental, além de ser um direito fundamental, é a oportunidade de proporcionar à população amazônica um crescimento socioeconômico afinado com a gestão ambiental. Para tanto, é necessário ação governamental. Contempla-se, na pesquisa, que essa intervenção do Poder Público é indispensável para proteger a dignidade da pessoa humana e também garantir os direitos constitucionais não só da população de hoje, mas, em especial, das gerações futuras.

Palavras-chave: Amazônia Legal; Problemas Sociais; Potencialidades e Desafios Amazônicos; Desenvolvimento Sustentável; Crescimento Econômico.

Abstract: The present study aims to analyze the challenges to be overcome to achieve sustainable development in the Legal Amazon. On the one hand, the incessant search for economic growth, on the other the need for social vitality and, finally, the universal requirement of environmental quality. Based on a documental-bibliographic research in the doctrine, jurisprudence and national and international legislation, it is demonstrated that environmental sustainability besides being a fundamental right is the opportunity to provide to the Amazonian population a socioeconomic growth in tune with the environmental management. This requires governmental action. It is contemplated, the research, that this intervention of the Public Power is indispensable to protect the dignity of the human person and also guarantee the constitutional rights not only to the population of today, but especially the future generations.

Keywords: Legal Amazon; Social Problems; Amazonian Potentialities and Challenges; Sustainable Development; Economic Growth.

1Universidade Federal do Ceará. E-mail: capsfi@hotmail.com, Link para o Lattes: http://lattes.cnpq.br/0854642119420091

revista brasileira educação ambiental 


\section{Introdução}

A Amazônia Legal assinala a intenção do governo da República Federativa do Brasil de planejar e promover o desenvolvimento social e o crescimento econômico dos estados - Amazonas, Pará, Acre, Rondônia, Roraima, Amapá, Tocantins e parte dos estados do Mato Grosso e Maranhão que, historicamente, convivem com os mesmos óbices econômicos, políticos e sociais. A definição é estabelecida no artigo $2^{\circ}$ da Lei № 5.173 , de outubro de 1966.

Portanto, abrange a área de cerca de sessenta por cento do território pátrio. Essa região é depositária de várias riquezas minerais e biodiversidades inexploradas. Possui o maior bioma brasileiro, corresponde a um terço das florestas tropicais úmidas e vinte por cento de toda a água doce do planeta. É o território que apresenta a mais elevada diversidade biológica do mundo. A Amazônia Legal é, estrategicamente, o celeiro da engenharia biotecnológica e do estudo em química fina.

Para desenvolver as necessidades dessa região, o poder público não só deve explorar as riquezas que coexistem nos diversos recursos naturais estratégicos, mas, também, perquirir 0 aprimoramento de índices socioeconômicos regionais e, principalmente, realizar integração da área das outras regiões do país. Tudo isso é comprovado por intermédio das visíveis potencialidades e dos obstáculos a serem superados no transcorrer do processo evolutivo.

Assim, a problemática consiste em como superar os desafios para que se alcance o desenvolvimento sustentável na Amazônia Legal. De um lado, a busca incessante do crescimento econômico, do outro, a necessidade de vitalidade social e, por fim, a exigência universal da qualidade ambiental.

Destarte, o estudo busca demonstrar que a sustentabilidade ambiental, além de ser um direito fundamental, é a oportunidade de proporcionar à população amazônica um crescimento socioeconômico afinado com a gestão ambiental. Para tanto, é necessário ação governamental.

Contempla-se na pesquisa que essa intervenção do poder público é indispensável para proteger a dignidade da pessoa humana e, também, garantir os direitos constitucionais não só da população de hoje, mas, em especial, das gerações futuras.

Em resumo, a metodologia desfrutada é analítica, empírica e crítica. Portanto, a análise é realizada com base em uma investigação documentalbibliográfica na doutrina jurisprudência e nas legislações nacional e internacional, que estão em sintonia com o tema. Esta é uma pesquisa pura por pretender engrandecer os conhecimentos. Da mesma forma, é qualitativa por empreender por meio da doutrina e do ordenamento jurídico nacional e internacional. Também é descritiva por esmiunçar a problemática explicando ponto a ponto. Além do mais, é exploratória, uma vez que pretende aperfeiçoar as ideias já debatidas em outros trabalhos. 
O desenvolvimento sustentável estabelece a relação do Estado com a sociedade amazônica. Assim, este artigo pretende analisar se ações e projetos incrementados pelo governo federal têm efetividade por assegurar 0 crescimento econômico e o direito ao meio ambiente sadio para as gerações futuras.

Para tanto, a pesquisa busca alcançar o objetivo macro de forma preliminar e procura abordar as generalidades e, em seguida, apresentar as peculiaridades psicossociais da região amazônica. Depois, mostrar as potencialidades e os desafios a serem superados e, imediatamente após, expor as ações e os projetos na busca do desenvolvimento sustentável. Por último, demonstrar a dicotomia crescimento econômico e sustentabilidade.

Assim, antes de se aprofundar na análise, é preciso conhecer as generalidades dessa região salutar.

\section{Amazônia Legal: Generalidades}

A Amazônia Legal é alvo da ampliação da fronteira agrícola do país. Esse crescimento desordenado contribui para a degradação do meio ambiente com o aumento das queimadas e, por conseguinte, do "arco de desmatamento". Esse conflito entre o desenvolvimento e a preservação dos recursos estratégicos é motivado pela potencialidade da região em maximizar os índices socioeconômicos regionais e, ao mesmo tempo, pela preocupação mundial com os reflexos ambientais por não a preservar.

Nesse caminho, é perceptível que o desenvolvimento sustentável é o modo de proteger o meio ambiente para as gerações futuras. É, também, o instrumento capaz de permitir o desenvolvimento socioeconômico e o bemestar das pessoas de maneira harmoniosa. Em âmbito governamental, portanto, precisa-se de projetos e ações direcionadas para concretizar a Amazônia Sustentável como meio norteador das políticas econômicas, sociais e territoriais da região.

Logo, de acordo com a Teoria dos Direitos Fundamentais, de Robert Alexy, apesar do Brasil ser um país soberano, o que, em linhas gerais, the assegura autonomia, o poder político deve ponderar a decisão de querer 0 desenvolvimento a qualquer custo, mesmo dentro do território nacional, em respeito às normas impostas nas relações internacionais, principalmente às convenções e aos tratados internacionais dos quais o Brasil é signatário. Dessa maneira, cabe ao Estado buscar conciliar, à defesa dos interesses nacionais, a prevalência dos direitos humanos e incrementar políticas públicas com capacidade de autodeterminação sobre o território em nome da nação e do povo sem ocasionar degradação exponencial ao meio ambiente (ALEXY, 2009, p. 70)

Do mesmo modo, a Amazônia Legal garante ao Brasil o aproveitamento de reservas de água doce. Água essa proveniente tanto da 
bacia hidrográfica quanto das subterrâneas em profusão. No entanto, o estudo permite perceber que essas reservas hídricas são impactadas com as progressivas buscas do desenvolvimento, já que o uso sem controle para a agricultura, a urbanização, as atividades de mineração e outros fins causam sérios danos ambientais.

Apesar das riquezas naturais e minerais, a Amazônia Legal possui pequena expressão no crescimento econômico nacional, já que a Participação no Produto Interno Bruto (PIB) é de cinco por cento no PIB brasileiro, ou seja, a menor contribuição entre todas as regiões do país. Verifica-se que a economia da região é impulsionada pelo extrativismo (látex, açaí, madeira, castanha e outros) e pela mineração (ferro, bauxita, manganês, ouro e nióbio). Desse modo, para adquirir maior notoriedade econômica regional e nacional, precisa potencializar as forças produtivas e gerar o mínimo de impacto ao meio ambiente.

De fato, a Amazônia Legal possui grandes potencialidades econômicas em termos de recursos minerais, vegetais ou humanos. Por isso, o governo federal necessita criar planos e ações sustentáveis, no sentido de fiscalizar e controlar a exploração e o uso desses bens estratégicos para o Brasil. Deve, inclusive, estar atento ao aumento do interesse internacional pela área e buscar distinguir a cobiça da verdadeira preocupação com o desenvolvimento sustentável.

Até porque, RODRIGUEZ (2010, p. 67), a hileia Amazônica apresenta um baixo desempenho em importantes indicadores sociais, como no Índice de Desenvolvimento Humano (IDH). Entretanto, o poder público não pode simplesmente aumentar o impacto sobre o meio ambiente regional, pois isso prejudica 0 desenvolvimento sustentável e pode comprometer todos os recursos estratégicos dessa e da futura geração. Isto posto, o desenvolvimento socioeconômico da Amazônia Legal deve ser fruto da gestão e do planejamento estratégico do governo federal, que precisa conciliar não só na integração territorial, como também no crescimento econômico, no desenvolvimento social e na preservação do meio ambiente.

Para isso, a Amazônia Legal deve consolidar o modelo de crescimento sustentável com base na inovação e na modernização dos atuais setores produtivos e sociais existentes. O governo federal, consequentemente, deve implementar ações ambientalmente equilibradas, de efeito dual, para proporcionar o desenvolvimento socioeconômico e servir de solução aos grandes desafios impostos à ascensão regional.

Desta forma, não deverá existir espaços na Amazônia Legal onde o Estado Brasileiro não projete influência adequadamente, pois, nesse vazio do estatal, proliferam-se os problemas ambientais e a cobiça internacional sobre recursos estratégicos, em especial, a água e os minérios de grande valor econômico. No mais, esse descaso do Estado leva a comunidade internacional a questionar a soberania brasileira sobre a Amazônia Legal, juridicamente, por meio da opinião pública internacional, que alega o direito de proteger as 
gerações futuras dos riscos ambientais e, a partir daí, passar a conceituá-la como patrimônio da humanidade.

O estudo torna notório que, em pleno século XXI, a Amazônia Legal permanece como a possibilidade da expansão capitalista em um contexto de interesses estratégicos. O que importa é o Brasil ser proativo e buscar conciliar desenvolvimento com a preservação ambiental.

\section{Peculiaridades psicossociais}

São várias as peculiaridades psicossociais vivenciadas pela população da Amazônia Legal. Por ironia, com potencial inversamente proporcional às riquezas inexploradas (naturais e minerais). Esse aspecto abrange 0 saneamento básico, a mortalidade infantil, as terras indígenas, a densidade demográfica e a expectativa de vida. Precisa reconstruir o conceito de desenvolvimento sustentável a partir da dimensão do índice de Desenvolvimento Humano (IDH) e não mais em termos de Produto Interno Bruto (PIB) (OLIVEIRA, 2010, p. 158).

Apesar da Lei de Saneamento Básico, № 11.445, de 5 de janeiro de 2007, ter inúmeros fundamentos que vão desde a universalização integralidade - utilização de tecnologia - controle social, a Amazônia Legal detém os municípios com os índices mais insignificantes do país; quando ordenado por zonas pela disponibilidade e eficácia de oferta de água e de esgoto, cita-se Ananindeua, Santarém (Pará) e Porto Velho (RO). Esse descaso dos poderes públicos federal, estadual e municipal promove a degradação ambiental e é fator de risco para o desenvolvimento sustentável.

Outro fator salutar é a mortalidade infantil. Observa-se um problema que pode ser reduzido ou extinguido se forem superados os desafios previstos na Agenda 21 da Conferência das Nações Unidas para o Meio Ambiente e Desenvolvimento, em 1992 (ECO-92), "A luta contra a pobreza". Com base nos dados da Organização Mundial de Saúde, a Amazônia Legal, em pleno século $\mathrm{XXI}$, ainda supera a média do país de doze por cento. A desigualdade social é ainda mais forte nessa região, propiciando, por exemplo, que o estado de Roraima apresente índice de mortalidade infantil com cerca de oito por cento acima da média nacional.

Também ocorre na região amazônica a ocupação de terras indígenas. Mesmo com o amparo na legislação vigente constitucional e infraconstitucional (Lei 6001/73 - Estatuto do Índio, Decreto no 1775/96), verifica-se o desrespeito à população indígena nas mais de quatrocentas terras indígenas da região, segundo dados do Programa de Monitoramento de Áreas Protegidas do Instituto Socioambiental (ISA). Essas ações ilícitas visam o desmatamento e a exploração ilegal de minério (garimpo). Esse é outro aspecto que enfraquece a sustentabilidade da área. 
Segundo THÉRY (2014, p. 89), dentro da disparidade nacional se encontra a dinâmica populacional. A Amazônia Legal sofre com esse problema por possuir vazios populacionais. Com cinquenta e nove por cento do território brasileiro, essa região detêm a densidade demográfica de 3,67 habitantes por quilômetro quadrado, ou seja, inferior a todas as outras das regiões do país.

Semelhantemente, de acordo como os dados disponibilizados pelo Instituto Brasileiro de Geografia e Estatística (IBGE), o brasileiro vive em média até os 75 anos. No entanto, ao comparar essa realidade com a expectativa de vida dos nove estados da região, observa-se que todos possuem índices inferiores à média nacional. Destacam-se os estados do Maranhão (70 anos) e Amazonas (71 anos), em 2015.

\section{Potencialidades e desafios Amazônicas}

As potencialidades e os desafios da Amazônia Legal são motivos correlatos no contexto da proteção ambiental no Brasil. Nessa região, predominam recursos vegetais e naturais estratégicos cujos controle e preservação representam um desafio para o desenvolvimento sustentável da federação brasileira.

A força normativa da Constituição $\operatorname{HESSE~(1991,~p.~18)~impõe~o~}$ cumprimento do que garante 0 Art. 225 da Constituição da República Federativa do Brasil, de 1988, que prevê como direito fundamental um "[...] meio ambiente ecologicamente equilibrado", e também declara que esse é "[...] bem de uso comum do povo e essencial à sadia qualidade de vida [...]" e ainda designa ao poder público e à coletividade "[...] o dever de defendê-lo e preservá-lo para as presentes e futuras gerações" (BRASIL, Constituição Federal de 1988).

É potencial o fato de a Amazônia Legal possuir grande jazidas de minérios, em especial, no estado paraense. São vários fatores que contribuem para essa potencialidade mineral, e o Brasil cresce economicamente por ser proprietário do mercado de recursos minerais que o faz circular, principalmente, por causa do minério de ferro, da bauxita e de manganês.

Outra potencialidade dessa região é o solo. Os estudos mostram que a terra é boa para o plantio de soja. Essa cultura (soja) é uma das responsáveis pela expansão da fronteira agrícola nacional na parte norte dos estados de Rondônia e Mato Grosso e ao sul do estado do Amazonas, o que permite alavancar o crescimento econômico, mas, se desordenado, também 0 desmatamento e a degradação do meio ambiente.

No mesmo significativo potencial é a expressiva reserva de água doce, superficial e subterrânea, da Amazônia Legal. Os recursos hídricos possuem grande valor econômico, que tanto podem fomentar o setor primário quanto o setor secundário das economias regional e nacional. O estudo deixa claro que cerca de vinte por cento de toda reserva do planeta de água doce se encontra 
na região. Além disso, é necessário expressar que os recursos fluviais da área dispõem de grande capacidade de geração de energia elétrica. Nesse sentido, fica evidente o tamanho hidrográfico da região.

Dessa maneira, a Amazônia Legal é exponencial no que tange à pesquisa na área da biotecnologia, dos cosméticos e das indústrias farmacêuticas. Também apresenta potencial em matéria-prima e recursos minerais, como o nióbio, principalmente em São Gabriel da Cachoeira-AM. Salienta-se o valor imensurável desse mineral para as indústrias espacial e nuclear.

Contudo, a Amazônia Legal também apresenta desafios a serem superados neste século. $O$ primeiro é a precária infraestrutura rodoviária, como BR-319 (Porto Velho - Manaus), BR-364 (Cuiabá - Porto Velho), BR-163 (Cuiabá-Santarém), BR-019 (Belém - Brasília) e BR-230 (Transamazônica Pará - Amazonas). A integração com as precárias condições da maioria dessas malhas rodoviárias significa graves transtornos por dificultar ou impedir o fluxo logístico com as demais regiões, em especial as regiões Centro-Oeste e Sudeste. O desfio é visível ao pesquisar o contexto de isolamento físico de Manaus-AM, o que aumenta os custos logísticos e impossibilita a variação de modal logístico. A manutenção e o projeto de pavimentação da BR-319 (Porto Velho-Manaus) são deveres do Estado, que tem a obrigação de viabilizar a conexão entre a metrópole da Amazônia Ocidental e o vetor de ocupação estabelecido em Rondônia.

Da mesma maneira, encontra-se o desafio para o incremento de novas usinas hidrelétricas por esbarrar em leis ambientais e terras indígenas. Existe tanto a corrente favorável ao crescimento e desenvolvimento quanto ao contrário, que preza pelo cumprimento dos direitos humano, fundamental e ambiental. Engradam-se nessa situação desfavorável que vem dificultando o prosseguimento das obras de Belo Monte (Pará), assim como Jirau e Santo Antônio (Rondônia).

Também o estudo possibilitou a percepção de que, apesar das ações do governo federal contínuo e continuado, ocorreu o aumento do desmatamento da Amazônia Legal. Os índices de devastação continuam altos, principalmente ao sul do Pará e Amazonas e ao norte dos estados de Rondônia e Mato Grosso. Tudo isso gera limitações ao desenvolvimento regional por intermédio de legislações e fiscalizações, que tentam dar sustentabilidade aos processos evolutivos.

De forma semelhante, mostra-se um desafio o baixo nível educacional dos integrantes da Amazônia Legal. É bom salientar que a força normativa da Constituição HESSE (1991, p. 19) assevera o explícito no Art. $6^{\circ}$ da Constituição Federal de 1988: o direito à educação. Uma ordem normativa é inquebrável, com isso, não pode ser remetido a segundo plano, principalmente em um Estado Democrático de Direito como o Brasil. Percebe-se que esse óbice contribui, de maneira desfavorável, ao desenvolvimento regional à medida que disponibiliza para o mercado de trabalho um profissional 
desqualificado. A região apresenta histórico de evasão escolar do Ensino Fundamental, além de outros fatores, como baixa média nacional de frequência do Ensino Médio, índices pequenos no Exame Nacional do Ensino Médio (Enem) e pouca disponibilidade de escolas técnicas e universidades.

Os desafios detalhados acima conduzem o pensamento de que os maiores problemas são a falta de efetividade das ações estatais, com fraco controle das atividades socioeconômicas desenvolvidas na região e a falta ou ineficiência de projetos governamentais de infraestrutura. Juntos, provocam déficit e limitações ao desenvolvimento econômico da área, assim como danos à saúde humana e, principalmente, perda de qualidade dos recursos naturais estratégicos.

À vista disso, a pesquisa sinaliza que as potencialidades inerentes à Amazônia Legal são significativas. Por tudo exposto, observa-se a capacidade de desenvolver, não só a região, mas todo o Brasil. Deve-se dar atenção, no entanto, às normas constitucionais e infraconstitucionais a fim de não comprometer a sustentabilidade destes para futuras gerações.

\section{Ações e projetos para o desenvolvimento sustentável}

Com dados oriundos de fontes do site do governo federal e conhecimentos do Ministério do Meio Ambiente, da Defesa, da Embrapa, do Ibama, do Incra, do Exército Brasileiro, do Inpe e do Serviço Florestal Brasileiro, fica perceptível, na pesquisa, a importância da intervenção governamental por meio de políticas públicas - ações e projetos - para transformar procedimentos arcaicos e destrutivos em hábitos modernos, sustentáveis e harmoniosos com a intenção de gerar resultados positivos e duráveis pela simples escolha de usufruir dos recursos estratégicos com medidas protetivas e de conservação.

Dessa maneira, a administração pública nacional trabalha para alcançar o desenvolvimento regional e, por conseguinte, o crescimento econômico do norte do país com mecanismos que zelam pelo meio ambiente, apesar de estimular a justiça social. Para isso, adotam a postura proativa que extirpa as ações devastadoras (desmatamentos e queimadas). Além disso, garantem orçamento para gerir as Unidades de Conservação e recursos para investir em infraestrutura de comunicação. Com tudo isso, o Estado oferece meios para que a Amazônia Legal se desenvolva de maneira sadia e sustentável.

Prosseguindo no azimute, observa-se que, para atingir os objetivos propostos no desenvolvimento sustentável na Amazônia, o governo federal procurou incrementar cerca de dez ações e projetos, dos quais se enumeram o Plano de Ação para Prevenção e Controle do Desmatamento na Amazônia Legal, o Programa Amazônia Sem Fogo, o Plano Amazônia Sustentável (PAS), o Sistema de Proteção da Amazônia (Censipam), o Programa Áreas Protegidas da Amazônia (Arpa), o Programa Assentamentos Verdes, o Programa Calha 
Norte, o Projeto Amazônia Conectada, além da Missão Amazônia e, na sequência, o Projeto Inventário Nacional.

Inicialmente está o Programa Calha Norte. No ano de 1985, esse instrumento surgiu como resposta à inquietude do poder nacional à cobiça internacional dissimulada às riquezas presentes na Amazônia. Devido à concepção, à abrangência e ao sentimento de dever de alguns órgãos públicos inseridos no processo, até hoje (2019), persegue a fomentar o desenvolvimento, a soberania e a integridade territorial do Brasil. É salutar que, sobre a gerência do Ministério da Defesa (1999), o Programa manteve o desígnio de estimular o aumento da densidade demográfica em harmonia com o desenvolvimento organizado e sustentável na Amazônia. Por isso, não se estagnou e passou a abranger cerca de 380 municípios espalhados nos nove estados da Amazônia Legal (Acre, Amapá, Amazonas, Pará, Rondônia, Roraima, Mato Grosso, Mato Grosso do Sul). A percepção é que o Estado tem que se fazer presente em todos os lugares. Deve estimular o sentimento de nacionalidade do povo com obras de infraestruturas e outras melhorias que agreguem na qualidade de vida e no bem-estar da sociedade local.

Depois, em 1999, o Instituto Brasileiro do Meio Ambiente e dos Recursos Renováveis (IBAMA), implantou o Programa Amazônia Sem Fogo. Menos impactante pelo objetivo específico de estimular a disciplina consciente dos habitantes locais para empregar técnicas alternativas às práticas agrícolas de queimar (fogo) para plantar. Por adotar atividades sistêmicas que alcançam a área formativa de capacitação, divulgação e negociação, as medidas sui generis de conscientizar - desenvolver - reduzir os incêndios florestais geram qualidade de vida e bem-estar aos produtores rurais.

Nessa senda, concebeu-se que o Ministério do Meio Ambiente é o responsável pelo incremento do Programa Áreas Protegidas da Amazônia (Arpa) - 2002 e, dos Planos: Ação para Prevenção e Controle do Desmatamento na Amazônia Legal (2004) e Amazônia Sustentável (PAS) 2008. O primeiro coordena o complexo programa de conservação florestal. O segundo adota como estratégia o monitoramento e o controle ambiental via satélite. Com o emprego de Tecnologia de Informação, consegue potencializar a área vigiada e, com isso, pretendia minimizar o desmatamento da região amazônica em oitenta por cento até 2020. Já o terceiro prioriza conscientizar a sociedade para o desenvolvimento sustentável da Amazônia e, para isso, prevê a redução das desigualdades regionais por intermédio da participação democrática dos governos dos estados da Amazônia Legal e da sociedade civil (consultas públicas) da região.

Em 2012, o Serviço Florestal Brasileiro na Amazônia impôs o Projeto Inventário Nacional, de responsabilidade da União Federal. Com incumbência de executar a coleta de dados biofísicos e socioambientais, consegue levantar o estoque de madeira, além de ter como propósito estudar a biodiversidade, o dinamismo das florestas, o índice de desenvolvimento e de bem-estar das populações da região. Todos os objetivos aqui alcançados são importantes 
para assessorar as elaborações de políticas públicas com o fim do uso e da conservação dos recursos florestais, dos estoques de carbonos e do respectivo manejo do território pelas comunidades da área.

No ano de 2013, o Instituto Nacional de Colonização e Reforma Agrária (INCRA) desenvolveu o Programa Assentamentos Verdes como estratégia de preservação. O objetivo era atingir, até 2019 , cerca de 980 áreas de reforma agrária em 199 municípios e abarcar 190 mil famílias. Mas, não somente isso, pois buscava realizar a regularização fundiária - ambiental e o controle no desmatamento ilegal nos assentamentos de reforma agrária na Amazônia.

Em evolução crescente, através da Portaria Interministerial № 586, de 22 de julho de 2015, o Ministério da Defesa coordena o Projeto Amazônia Conectada e, por meio do Centro Gestor e Operacional do Sistema de Proteção da Amazônia (Censipam), disponibilizou, em 2016, a tecnologia que promove o monitoramento da Amazônia. Ambos simbolizam a modernidade; o Projeto Amazônia Conectada por universalizar a infraestrutura de comunicação, internet de Banda Larga na Amazônia, e o Censipam por possibilitar dar alertas de desmatamento com radar orbital.

Ainda, como instrumento de desenvolvimento sustentável à região, implementou-se o projeto Missão Amazônia, do Instituto Nacional de Pesquisas Espaciais (Inpe), que desenvolveu o preambular satélite com concepção, teste e operação nacional, denominado Amazônia-1. Essa tecnologia promove o sensoriamento em tempo real e, por isso, monitora o desmatamento, principalmente na Amazônia Legal, além da diversificada agricultura em todo Brasil. Por atuar em sinergia com outros Programas, os dados adquiridos são fundamentais para cumprir as demandas ambientais e, ainda, para acompanhar assuntos de notória importância socioeconômicos que vão desde desastres ambientais - faixa litorânea - bacias hidrográficas - florestas nativas e sustentáveis.

No entanto, além de estudar as ações e os projetos para o desenvolvimento sustentável, é importante, para o enfoque Amazônia Legal, abordar ainda a temática crescimento econômico e sustentabilidade, já que a pesquisa mostra que, apesar das dificuldades, há maneiras de conciliar estes dois interesses por vezes discrepantes.

Primeiro, o Plano de Prevenção e Controle do Desmatamento da Amazônia (PPCDAM), do governo federal, de 2004, serve como ilustração. Por meio desse instrumento, o Ministério do Meio Ambiente busca quebrar paradigmas e, com racionalidade, passar a conscientizar os madeireiros. Assim, para almejar atingir a sustentabilidade, inicialmente, alcança a "redução do desmatamento" e mais, "atraiu a atenção da comunidade internacional". Tudo isso só foi possível por conseguir "reduzir de forma contínua e consistente o desmatamento". Portanto, o ciclo produtivo da derrubada da floresta, da produção de madeira para a exportação ou para o mercado interno, da produção de carvão, largamente empregado nas siderurgias que fabricam ferro, passam a acontecer em um "modelo de desenvolvimento sustentável". 
De forma similar, outra ação governamental, visando alcançar crescimento econômico com sustentabilidade, foi o Plano Nacional sobre Mudanças Climáticas (PNMC) - 2008. Nesse caso, surgiu como mecanismo de controle da expansão da pecuária na Amazônia. Com metas "que se reverterão na redução de emissões de gases de efeito estufa, além de outros ganhos ambientais e benefícios socioeconômicos". Assim, o Plano vem de encontro ao aumento da pecuária dentro do "Arco do Desmatamento". Uma das metas é "reduzir o índice de desmatamento anual da Amazônia (redução de oitenta por cento até 2020)".

No mesmo sentido, apresenta-se mais um processo de crescimento econômico com sustentabilidade na instalação da Usina Hidrelétrica (UHE) de Tucuruí - Eletrobrás. É necessário entender que a infraestrutura hidroelétrica é fundamental para o desenvolvimento da Amazônia Legal e, para isso, se faz necessário aproveitar o potencial dos rios da região. Dessa maneira, a UHE Tucuruí é concebida como a principal usina integrante do Subsistema Norte do Sistema Interligado Nacional (SIN). Tem a incumbência de prover energia elétrica para os estados do Pará, Maranhão e Tocantins. Na concepção e operacionalidade da obra foi necessário cumprir os rituais burocráticos para minimizar os efeitos colaterais dessa obra que induz progresso.

\section{Conclusão}

A Amazônia Legal é constituída de potencialidades e desafios que permeiam as riquezas a serem exploradas de forma responsável em prol do bem comum e do interesse coletivo.

O desenvolvimento sustentável é a melhor maneira para usufruir dos potenciais existentes na região. A exploração das capacidades deve ocorrer em harmonia com a preservação ambiental, para que, junto com o crescimento econômico, estejam o desenvolvimento humano e social de todos.

Em síntese, a predatória atitude do homem em explorar indiscriminadamente as riquezas naturais e minerais descobertas na Amazônia fomenta a destruição e contribui para a extinção do ciclo necessário à vida humana. O impacto do homem no meio ambiente destrói não só a biodiversidade, mas todos os bens que possam ser úteis ao crescimento econômico, ao desenvolvimento social e ao meio ambiente a médio e longo prazo.

De fato, explorar os recursos minerais e vegetais existentes na Amazônia proporciona o aumento do Produto Interno Bruto, que, apesar de ser favorável à balança comercial, causa sérios impactos ao meio ambiente. Observou-se a colisão de interesses frente às potencialidades apresentadas. Essa extensa região é exponencial e, por isso, detém um misto de riqueza estratégica necessária à sociedade de várias gerações para melhorar os índices de desenvolvimento humano e econômico. 
Os desafios são inúmeros e exigem ações e projetos efetivos do Estado para explorar sem destruir e para atender, invariavelmente, ao interesse da população no que diz respeito ao desenvolvimento social e ao viver com dignidade. Destarte, é importante apaziguar o litígio para que as gerações de hoje e as vindouras possam usufruir dos mesmos direitos de se ter uma região ecologicamente equilibrada. Além disso, balizada por normas transparentes e eficientes que protejam a Amazônia Legal e diminuam a desigualdade socioeconômica dos habitantes da região.

Dessa forma, existem mecanismos que permitem que os desafios sejam superados e, com isso, se passe a viver de maneira equilibrada e desfrutando dos benefícios trazidos pelo desenvolvimento sustentável na região. Logo, os conflitos (potencialidades e desafios) geram consequências ao meio ambiente, que precisam ser minimizados por meio de procedimentos civis, administrativos ou penais para coibir os atos ilícitos, já que a omissão causa grave prejuízo a todos. Também é preciso realizar o Estudo de Impacto Ambiental (EIA) antes de iniciar a exploração mineral para evitar consequências negativas e a degradação do meio ambiente.

Por fim, o desenvolvimento sustentável requer a exploração dos recursos minerais e vegetais de acordo com as corretas técnicas de manejo ambiental previstas nas normas vigentes no ordenamento jurídico brasileiro.

\section{Referências}

ALEXY, R. Teoria dos Direitos Fundamentais. São Paulo. Malheiros, 2008.

BECKER, B.K. Amazônia: geopolítica na virada do III milênio. Rio de Janeiro: Garamond, 2007.

BECKER, B.K.; EGLER, C.A.G. Brasil uma nova potência regional na economia-mundo. Rio de Janeiro: 4ª edição, Bertrand Brasil, 2003.

BRASIL. Ministério da Defesa. Disponível em: <http://www.sipam.gov.br/ assuntos/projeto-amazonia-sar >. Acesso em: 16 de junho de 2019.

BRASIL. Ministério do Meio Ambiente. Disponível em: <http://www.mma.gov. br/florestas/controle-e-preven\%C3\%A7\%C3\%A3o-do-desmatamento/plano amaz\%C3\%B4nia-sustent\%C3\%A1vel-pas>. Acesso em: 16 de junho de 2019.

BRASIL. Constituição da República Federativa do Brasil, 1988.

BRASIL. Instituto Brasileiro do Meio Ambiente e dos Recursos Renováveis (IBAMA). Disponível em: < http://www.ibama.gov.br/prevfogo/132-fiscalizacaoe-protecao/incendios-florestais/780-programa-amazonia-sem-fogo >. Acesso em: 16 de junho de 2019.

BRASIL. Instituto Nacional de Colonização e Reforma Agrária (INCRA). Disponível em: <http://www.incra.gov.br/sites/default/files/uploads/reformaagraria/analise-balanco-e-diagnosticos/boletins-assentamentosverdes/boletim 03 0.pdf>. Acesso em: 16 de junho de 2019. 
BRASIL. Instituto Nacional de Pesquisas Espaciais (INPE). Disponível em: <http://www.inpe.br/amazonia-1/>. Acesso em: 16 de junho de 2019.

BRASIL. Ministério da Defesa. Disponível em: $<$ http://www.amazoniaconectada.eb.mil.br/pt/ >. Acesso em: 16 de junho de 2019.

BRASIL. Ministério da Defesa. Disponível em: $<$ http://www.defesa.gov.br/programas-sociais/programa-calha-norte $>$. Acesso em: 16 de junho de 2019.

BRASIL. Ministério do Meio Ambiente. Disponível em: <http://programaarpa.gov.br/ >. Acesso em: 16 de junho de 2019.

BRASIL. Ministério do Meio Ambiente. Disponível em: $<$ http://www.mma.gov.br/informma/item/616-prevenção-e-controle-dodesmatamento-na-amazônia >. Acesso em: 16 de junho de 2019.

BRASIL. Ministério do Meio Ambiente. Disponível em: $<$ http://www.mma.gov.br/component/k2/item/616? ltemid=1155>. Acesso em: 16 de junho de 2019.

BRASIL. Plano Amazônia Sustentável (PAS). Disponível em: $<$ http://mma.gov.br/floresta/controle-e-preven\%C3\%A7\%C3\%A3o-dodesmatamento/plano-amaz\%C3B4nia-sustent\%C3\%A1vel-pas>. Acesso em: 14 de junho de 2019.

BRASIL. Serviço Florestal Brasileiro. Disponível em: $<$ http://www.florestal.gov.br/inventario-florestal-nacional>. Acesso em: $16 \mathrm{de}$ junho de 2019.

HESSE, K. A força normativa da constituição / Konrad Hesse, tradução Gilmar Mendes. - Porto Alegre, 1991.

OLIVEIRA, G.C. A Logística Reversa como Instrumento do Desenvolvimento Sustentável. Hiléia-Revista do Direito Ambiental da Amazônia. Ano5nํ9, UEA,-Edições, 2007.

PORTO-GONÇALVES, C.W. Os (des)caminhos do meio ambiente. 6 $6^{\underline{a}}$ ed. São Paulo: Ed. Contexto, 1998.

RODRIGUEZ, J.M.M. Educação ambiental e desenvolvimento sustentável: Problemática, tendências e desafios. 2. Ed. Reimpressão. / José Manuel Mateo Rodriguez e Edson Vicente da Silva. - Fortaleza: Edições UFC, 2010.

ROSS, J.L.S. A Sociedade Industrial e o Ambiente. In: Geografia do Brasil. 5ª ed. São Paulo: Edusp, 2008.

THÉRY, H.; MELLO, N.A. Atlas do Brasil: Disparidades e Dinâmica do Território. São Paulo: Imprensa Oficial. 2 edições. 2008. 